\title{
A Comprehensive review of abdominal infections
}

\author{
Nicole Lopez ${ }^{1}$, Leslie Kobayashi ${ }^{*}$, Raul Coimbra ${ }^{3}$
}

\section{Introduction}

Intra-abdominal infection (IAI) is an important cause of morbidity and mortality. It is the second most commonly identified cause of severe sepsis in the intensive care unit (ICU). Recent studies have associated severe intra-abdominal infection with a significant mortality rate.

Most IAI are a result of processes involving inflammation and perforations of the gastrointestinal tract, such as appendicitis, peptic ulcer disease, and diverticulitis. Patients with diffuse peritonitis may be due to spontaneous perforation, post-operative, post-interventional or post-traumatic causes. The lower GI tract is most often the location of perforation. Among patients with IAI who develop peritonitis, many may progress to severe sepsis, defined by The American College of Chest Physicians/Society of Critical Care Medicine as a severe systemic inflammatory response to infection that is associated with acute organ dysfunction.

Successful treatment of IAI is based on early and appropriate source recognition, containment and antimicrobial coverage. We will review clinical definitions, pathophysiology, and treatment strategies for IAI in an effort to provide guidelines for clinical management.

\section{Definitions}

Intra-abdominal infection (IAI) describes a diverse set of diseases. It is broadly defined as peritoneal inflammation in response to microorganisms, resulting in purulence in the peritoneal cavity [1]. IAI are classified as uncomplicated or complicated based on the extent of infection [2].

Uncomplicated abdominal infections involve intramural inflammation of the gastrointestinal (GI) tract without anatomic disruption. They are often simple to treat; however, when treatment is delayed or inappropriate, or the infection involves a more virulent nosocomial

\footnotetext{
* Correspondence: Ikobayashi@ucsd.edu

${ }^{2}$ Assistant Professor of Surgery, University of California, San Diego, 200 W.

Arbor Dr. \#8896, San Diego, CA 92103-8896, USA

Full list of author information is available at the end of the article
}

microbe, the risk of progression into a complicated abdominal infection becomes significant $[3,4]$.

Complicated abdominal infections extend beyond the source organ into the peritoneal space. They cause peritoneal inflammation, and are associated with localized or diffuse peritonitis[5]. Localized peritonitis often manifests as an abscess with tissue debris, bacteria, neutrophils, macrophages, and exudative fluid contained in a fibrous capsule. Diffuse peritonitis is categorized as primary, secondary or tertiary peritonitis.

Primary peritonitis is also known as spontaneous bacterial peritonitis. It is thought to be the result of bacterial translocation across an intact gut wall [6]. These infections are commonly monomicrobial, and the infecting organism is primarily determined by patient demographics. For example, healthy young girls are most often infected by streptococcal organisms, cirrhotics by gram negative or enterococcal organisms, and peritoneal dialysis patients by Staphylococcus aureus $[7,8]$. Diagnosis requires peritoneal fluid aspiration. Characteristics of infection include white blood cell count (WBC) > 500 cells $/ \mathrm{mm}^{3}$, high lactate, and low glucose levels. Positive peritoneal fluid cultures are definitive, and resolution of infection is marked by peritoneal fluid with $<250$ $\mathrm{WBC} / \mathrm{mm}^{3}[9]$.

Secondary peritonitis is caused by microbial contamination through a perforation, laceration, or necrotic segment of the GI tract[7]. Definitive diagnosis is based on clinical examination and history, and specific diagnoses can be confirmed by radiographic imaging[10]. If a patient is stable enough for transport, computed tomography $(\mathrm{CT})$ scan with intravenous and oral contrast is the standard method of evaluating most intra-abdominal pathologies, such as appendicitis, diverticulitis, and colitis [11]. Suspected biliary pathology is the exception, and ultrasound is the preferred initial imaging modality for this spectrum of disease including acute cholecystitis, emphysematous cholecystitis, and cholangitis. Infections associated with secondary peritonitis are commonly polymicrobial and the infecting organisms are those most commonly associated with the source of contamination (see Table 1). 
Table 1 Expected organisms according to source

\begin{tabular}{|c|c|c|}
\hline & Source & Expected Organism \\
\hline \multirow[t]{3}{*}{$\begin{array}{l}\text { Primary } \\
\text { Peritonitis }\end{array}$} & $\begin{array}{l}\text { Young healthy } \\
\text { female }\end{array}$ & Streptococcus \\
\hline & Cirrhotic & Enteric gram negatives Enterococcus \\
\hline & CAPD & Staphylococcus aureus \\
\hline \multirow[t]{4}{*}{$\begin{array}{l}\text { Secondary } \\
\text { peritonitis }\end{array}$} & $\begin{array}{l}\text { Stomach and } \\
\text { duodenum }\end{array}$ & Streptococcus Lactobacillus \\
\hline & Biliary & E. coli, Klebsiella, Enterococcus \\
\hline & Small Intestine & $\begin{array}{l}\text { E. coli, Klebsiella, Lactobacillus } \\
\text { Streptococci Diptheroids Enterococci }\end{array}$ \\
\hline & $\begin{array}{l}\text { Distal ileum } \\
\text { and colon }\end{array}$ & $\begin{array}{l}\text { Bacteroides fragilis Clostridium spp. E. } \\
\text { coli Enterobacter spp. Klebsiella spp. } \\
\text { Peptostreptococci Enterococci }\end{array}$ \\
\hline $\begin{array}{l}\text { Teritiary } \\
\text { peritonitis }\end{array}$ & & $\begin{array}{l}\text { Enterococcus Candida Staphylococcus } \\
\text { epidermidis Enterobacter }\end{array}$ \\
\hline
\end{tabular}

Adapted from Weigelt JA [12].

Tertiary peritonitis represents an infection that is persistent or recurrent at least 48 hours after appropriate management of primary or secondary peritonitis. It is more common among critically ill or immunocompromised patients [12]. Because of the poor host defenses, it is also often associated with less virulent organisms, such as Enterococcus, Candida, Staphylococcus epidermidis, and Enterobacter[13].

Intra-abdominal sepsis is an IAI that results in severe sepsis or septic shock[2].

\section{Pathophysiology}

The peritoneum divides the abdomen into the peritoneal cavity and the retroperitoneum. The peritoneum is a layer of mesothelium that lines the abdominal cavity. It is abundantly innervated by the somatic nervous system. This explains the intense localized pain that patients experience when they have peritoneal inflammation or injury. Functionally, it provides approximately one $\mathrm{m}^{2}$ of exchange area, and holds approximately $100 \mathrm{ml}$ of peritoneal fluid, primarily consisting of macrophages and lymphocytes[14,15]. Negative pressure generated by diaphragmatic relaxation causes peritoneal fluid to flow upward toward a specialized system of diaphragmatic fenestrae. This high flow system drains fluid into the lymphatic system. During infection, this allows for rapid efflux of micro-organisms and host defenses into the venous system via the thoracic duct [16].

Perforation, and the bacterial innoculation that ensues, causes an inflammatory response that acts locally to contain the infection; but, in the setting of overwhelming contamination, it can spread to cause systemic inflammation.

Several mechanisms act locally to contain or destroy infection. Tissue injury stimulates mast cell degranulation. Mast cell degranulation releases histamine, kinins, leukotrienes, prostacyclines, and free radicals. These factors increase vascular and peritoneal permeability allowing for local influx of complement and coagulation cascade factors.

Influx of complement at the site of contamination allows for bacterial opsonization via C3b. Diaphragmatic motion, described above, then leads to absorption of bacteria laden peritoneal fluid into the lymphatic system. Opsonised organisms in the lymph are transported to the reticuloendothelial system, where they are destroyed. In addition to bacterial destruction via opsonization, complement also attracts neutrophils to the site of injury via chemotactic factors C3a and C5a. Neutrophils attack bacteria by three mechanisms: first they express and release more cytokines further propagating the inflammatory response; second, they phagocytose and destroy bacteria via respiratory burst; third they secrete neutrophil extracellular traps (NETs). NETs are composed of DNA, chromatin and serine proteases. NETs can both destroy extracellular organisms without phagocytosis, and act as a physical barrier to prevent the further spread of pathogens [17]. Finally, tissue factor, expressed by injured tissue, leads to activation of the coagulation cascade. This results in increased fibrin production, necessary to contain bacteria by abscess formation.

These cellular processes can also have systemic effects, as the products of mast cell degranulation at the site of injury move into the circulatory system. There, in addition to increased vascular permeability, they cause smooth muscle relaxation and can result in peripheral vascular collapse. Free radicals released with degranulation cause lipid peroxidation of cell membranes resulting in further release of toxic granulation products. Granulocytes and macrophages, attracted to the site of injury by the complement chemotactic factors C3a and C5a, release acute phase cytokines such as IL-1, IL-6, TNF- $\alpha$, IFN- $\gamma$. These cytokines are released into the peripheral circulation where they cause fever, cortisol release, acute phase protein synthesis, leukocytosis, and lymphocyte differentiation and activation. The resultant physiologic state is clinically known as the Systemic Inflammatory Response Syndrome (SIRS). SIRS is defined by the presence of at least two of the following: core body temperature $>38^{\circ} \mathrm{C}$ or $\left\langle 36^{\circ} \mathrm{C}\right.$, heart rate $>$ 90 beats per minute, respiratory rate $>20$ breaths per minute (not ventilated) or $\mathrm{PaCO}_{2}<32 \mathrm{mmHg}$ (ventilated), $\mathrm{WBC}>12,000,<4,000$, or $>10 \%$ immature forms (bands)[18]. When SIRS is associated with a bacterial source, as with cases of IAI, it is known as sepsis. When sepsis is paired with organ failure, it is known as severe sepsis.

\section{Management}

Management of IAI requires resuscitation, source control, and antibacterial treatment. The most important of 
these factors is source control, which, "encompasses all measures undertaken to eliminate the source of infection and to control ongoing contamination"[19]. There are three key components of source control: drainage, debridement, and definitive management.

\section{Resuscitation and Support of Organ Systems}

IAI causes volume depletion by several mechanisms. Nausea, anorexia and ileus lead to a decrease in oral intake, while vomiting and diarrhea increase sensible losses. In addition, ileus with third space losses into the bowel wall and ascites, as well as fever both increase insensible losses. Elevated body temperature leads to both an increase in dermal loss via sweating, and an increase in respiratory loss by causing tachypnea. Dermal loss in a febrile patient can account for approximately $600 \mathrm{ml}$ of volume loss per day, while tachypnea causes approximately $100 \mathrm{ml}$ of volume loss per day [20,21].

In uncomplicated IAI, replacing volume is essential; in severe sepsis or septic shock, it becomes critical. Patients suspected of having severe sepsis or septic shock should be admitted to an ICU for careful monitoring of vital signs and volume status. With regard to the initial volume resuscitation, we recommend following the Surviving Sepsis Campaign recommendations. As soon as hypotension is recognized, or, ideally if it is anticipated, attention should be paid to early goal directed volume resuscitation. Isotonic fluid, or in the cases of severe anemia or coagulopathy, blood products, should be administered with the intent to achieve a mean arterial pressure (MAP) $>65 \mathrm{mmHg}$ and a central venous pressure (CVP) of 12-15 $\mathrm{mmHg}$ within the first 6 hours [22]. If a MAP $>65 \mathrm{mmHg}$ cannot be obtained by volume resuscitation alone then vasopressors should be used, with a preference for norepinepherine or dopamine [22]. In cases where low cardiac output or elevated filling pressures indicate severe myocardial dysfunction, use of inotropic agents such as dobutamine may be efficacious in obtaining adequate MAP [22]. Care should also be taken to monitor clinical indicators of end organ perfusion, such as hourly urine output and mental status, to ensure adequate oxygen delivery.

The goal of resuscitation is correction of cellular oxygen debt. Various endpoints for resuscitation have been suggested, including: mixed venous oxygen $\left(\mathrm{SVO}_{2}\right)$, lactate and base deficit. While a normal or high $\mathrm{SVO}_{2}$ does not ensure adequate tissue oxygenation, a low $\mathrm{SVO}_{2}$ indicates a need to increase tissue oxygenation. Resuscitation to maintain an $\mathrm{SVO}_{2}>65 \%$ has been shown to improve outcomes [23,24]. Lactate, a product of anaerobic metabolism, has also been used as an indirect measure of oxygen debt. More recently sepsis has been recognized as a hypermetabolic state that uses glycolysis in the absence of hypoxia, making it less reliable as a marker of oxygen debt. Still, its early normalization may predict improved outcomes [25-27]. Base deficit is yet another indicator of oxygen debt. It describes the amount of base that would be required to bring the blood to a normal $\mathrm{pH}$ under normal physiologic conditions. The degree of base deficit has been shown to correlate with resuscitation requirements and mortality $[28,29]$. While none of these measures are perfect, they can be helpful in guiding resuscitation when used in combination with the other clinical endpoints discussed above.

\section{Drainage}

The goal of drainage is to evacuate purulent, contaminated fluid, or to control drainage of ongoing enteric contamination. This is accomplished by either percutaneous or open surgical intervention. Percutaneous drainage can be performed with or without image guidance, and is most commonly performed using ultrasound or CT. In many circumstances it is as efficacious as surgical drainage, and is often used as the initial treatment of choice because it is less invasive and more affordable [30,31]. Percutaneous drainage is also useful in patients who are poor surgical candidates, and might not survive definitive surgical treatment. However, percutaneous drainage is unlikely to result in adequate source control in cases of frank bowel perforation with ongoing contamination, or if there is a significant amount of necrotic tissue present. In these cases, surgery is the treatment of choice.

Open surgical drainage should be used in the case of generalized peritonitis, ongoing gross contamination from an uncontrolled enteric source, if bowel necrosis or ischemia is suspected, and in cases of failure of percutaneous drainage. Unstable patients, or those with complicated or difficult anatomy such as post-operative patients or those with advanced malignancy pose a particular challenge.

In these situations, damage control techniques can be employed with temporary abdominal closure. Damage control procedures are typically used for patients who are unstable and unable to tolerate definitive surgical treatment, have intra-abdominal hypertension (IAH), or have loss of abdominal domain that prevents fascial closure. The first stage in damage control surgery is evacuation of infected material and control of gross contamination. This is followed by temporary abdominal closure with a conventional dressing, negative pressure dressing, or skin closure. This first operative stage is followed by ongoing resuscitation, once normal physiology is restored resuscitation can then be followed by planned re-laparotomy for definitive source control and reconstruction. In cases of physiologic worsening after first laparotomy, or in cases of concern for IAH, or intestinal ischemia, on demand repeat laparotomy can 
be performed. Once all surgical issues have been addressed, physiology has been restored and there are no longer concerns for ongoing ischemia, necrosis, or IAH the abdomen can be definitively closed.

Intra-abdominal lavage is a subject of ongoing controversy. Proponents of peritoneal lavage reason that contamination is both removed and diluted by lavage volumes greater than $10 \mathrm{~L}$, additionally, by adding antibiotics bacterial pathogens can be specifically targeted. One group has suggested that lavage with volumes of approximately $20 \mathrm{~L}$ reduces infectious complications in blunt traumatic small bowel perforation [32]. However, its application with or without antibiotics in abdominal sepsis is largely unsubstantiated; at this time there is minimal evidence in the literature to support its use $[33,34]$.

\section{Debridement}

Debridement is essential for removal of foreign bodies, fecal matter, hematoma, and infected or necrotic tissue. The necessity to remove fibrin deposits is controversial. One early study showed improved postoperative courses with fewer continued infections; however, more recent studies have shown no benefit to this strategy $[35,36]$.

\section{Definitive management}

Definitive management involves restoration of anatomy and function. While staged procedures were once the standard, single stage procedures with primary anastomoses have become accepted as both safe and cost effective in the stable patient [37]. Still, establishing bowel continuity may need to be delayed in patients who are unable to tolerate a lengthy procedure or have inadequate capacity for tissue healing [38].

\section{Specific Surgical Pathologies}

\section{Appendicitis}

Acute appendicitis is the most common intra-abdominal surgical emergency [19]. Lifetime risk is approximately 7-9\% [39]. Currently, imaging is recommended for all patients suspected of having appendicitis except men under 40 years of age [40]. Generally, CT scan is the accepted imaging modality, however, ultrasound may have a role in women at risk for other pelvic pathologies, in pregnancy and in children [41]. The sensitivity and specificity of CT scan in the diagnosis of acute appendicitis are $87-100 \%$ and $91-98 \%$, respectively $[42,43]$. Ultrasound is very user dependent, and results can be affected by patient body habitus, however overall sensitivity is $76-96 \%$ and specificity is $91-100 \%$ [44]. Ultrasound, with its decreased cost, lack of ionizing radiation and ability to assess ovarian pathology, has been the preferred initial imaging modality in children [45-47]. However, CT should be used in children when the initial ultrasound is negative or non-diagnostic and there is a high clinical suspicion for appendicitis $[45,48]$. Ultrasound is also the initial imaging procedure of choice in pregnant women, however, the appendix is visualized only $13-50 \%$ of the time. Magnetic resonance imaging (MRI) is an emerging imaging modality for cases of appendicitis in pregnancy with non-visualization of the appendix on ultrasound. Its sensitivity and specificity are $100 \%$ and $93.6 \%$, respectively [49].

Though acute appendicitis is a very common entity, its management still contains areas of controversy including the role of laparoscopy, and the emerging role of medical management. These decisions can be complicated by the presence of an abscess or phlegmon.

Surgical management of acute appendicitis has been the gold standard of treatment for decades. However, many groups have proposed that in select patients, acute uncomplicated appendicitis can be treated with antibiotics alone. Initial success rates for conservative management of acute appendicitis range from $88-95 \%$; however, recurrence is common, occurring in up to $35 \%$ of cases [50].

Both laparoscopic and open appendectomy are safe and effective. In large reviews, laparoscopic appendectomy has been associated with fewer surgical site infections, less pain, shorter hospital stays, and more rapid return to normal activity [51]. Common disadvantages found include increased cost and longer operative times $[52,53]$. Additionally, laparoscopy has been associated with increased risk of intra-abdominal abscess formation, especially in the presence of perforation or gangrene. In these cases, open surgery may be preferred [54]. Ultimately, the differences in outcomes between laparoscopic and open appendectomy are largely equivocal and the decision should be based on available technology and surgeon expertise, with increased consideration for laparoscopy in young female or obese patients $[51,55,56]$.

Management of patients presenting with abscess or phlegmon is conservative, with antibiotics and drainage initially. Traditionally this has been followed by interval appendectomy. However, recently the need for interval appendectomy has been questioned. Controversy primarily surrounds the issues of recurrence and potential for malignancy. In a large review the recurrence rate was $7.4 \%$ and the risk of malignancy $1.2 \%$ [57]. This is in accord with similar studies that conclude that in asymptomatic patients, interval appendectomy has no advantages over a thorough work up for inflammatory appendiceal masses [58,59].

\section{Gastroduodenal perforation}

After bleeding, perforation is the second most common complication requiring emergent operative intervention 
in peptic ulcer disease [60,61]. Helicobacter pylori infection is the most common cause of gastric and duodenal ulcers. Since the development of treatments for H. pylori, its prevalence in the United States has decreased. However, prevalence of gastric and duodenal ulcers has remained the same [62].

Previously, ulcer perforation was treated by excision and vagotomy. However, with antimicrobial eradication and anti-secretory pharmaceuticals, $H$. pylori positive ulcer recurrence has been significantly reduced [63]. As a result, the current standard of care is simple ulcer excision and primary repair of the bowel defect, or omental patch and subsequent $H$. pylori eradication, with little or no role for anti-secretory ulcer surgery $[61,64]$.

Both open and laparoscopic approaches are reasonable options for treatment of perforated peptic ulcers. Laparoscopic surgery is associated with significantly less pain, but downfalls include longer operative times, and potentially inadequate repair of large perforations. Comparisons of sutured versus non-sutured repair with fibrin glue plug reveal that both are safe [65].

Conservative management has also been proposed as a safe option for management of contained or sealed gastroduodenal perforations. One randomized study showed similar morbidity and mortality for operative and conservative approaches; however, conservative treatment was associated with longer hospital stays and increased failure in patients over 70 years old [66]. Similarly, another author suggests that patients less than 40 years old and not on NSAIDS are the most likely to be infected with $H$. pylori and therefore, the most likely to benefit from non-operative therapy [67]. Alternatively, one group suggests that non-operative therapy can be guided by documented self-sealing on gastroduodenogram [68].

\section{Diverticulitis}

Diverticular disease has increased since the turn of the 20th century [69]. The prevalence of diverticular disease among the general population is unknown, but at autopsy more than $50 \%$ of people over 80 years old are affected [70]. The lifetime prevalence of diverticulitis among patients with diverticulosis is 10-25\% [69].

The standard treatment for uncomplicated diverticulitis is bowel rest and antibiotics. Most patients with uncomplicated diverticulitis respond to conservative management. Two studies found that patients who did not respond to antibiotics within 48 hours were more likely to require prolonged hospital stays for IV antibiotics and/or surgical intervention [71,72].

Diverticulitis can be complicated by phlegmon, abscess, or free perforation and is generally classified according to modified Hinchey criteria [73]. Approximately 15-20\% of cases are associated with abscesses [74]. In cases of uniloculated abscess, the initial treatment is usually percutaneous drainage; although, in small abscesses $(<4$ $\mathrm{cm})$, antibiotics have been used as a primary treatment with success rates comparable to drainage $[75,76]$. When percutaneous drainage is performed it has success rates of up to $90 \%$ [77]. Of importance, the success of percutaneous drainage also seems to be dependent upon location. Ambrosetti and colleagues found that compared to mesocolic abscesses, pelvic abscesses were more aggressive, needed earlier drainage, and were more likely to require surgery [78].

Traditionally, patients who present with an abscess or phlegmon then undergo elective surgery to avoid the high risk of recurrence and further complications [71,73]. Recently though, some have begun to question the need for operative therapy when initial management with percutaneous drainage and antibiotics is successful [79]. Two authors have found that perforation, which is the most common cause of mortality in complicated diverticulitis, is more likely to be the initial presentation of disease, rather than a manifestation of recurrence $[79,80]$. They concluded that abscesses in complicated diverticulitis might then be adequately managed with antibiotics and drainage alone.

While conservative management may be appropriate in uniloculated abscesses, timely initial operative management is required for cases in which abscesses are large, multiloculated, or inaccessible, as well as in cases of free perforation, or diffuse peritonitis. Acute diverticulitis is complicated by free perforation in approximately $1.5 \%$ of episodes [81]. The standard procedure in cases of peritonitis is a Hartmann's procedure. However, the Hartmann's procedure is associated with significant morbidity and mortality, and while it can be reversed in 3-6 months, $30-70 \%$ of patients never undergo reversal [82-86]. Recently, it has been suggested that primary resection and anastomosis should be preferred $[83,86,87]$. Finally, laparoscopic resections for complicated diverticulitis have also been shown to be safe; and, in spite of longer operative times, they are associated with fewer major complications, less pain, and shorter hospital stays [88].

\section{Antibiotic Therapy}

Surgery is the definitive treatment for complicated IAI, but systemic antibiotic therapy is a necessary adjunct. The role of antibiotics in this setting is prevention and treatment of hematogenous spread of infection and reduction of late complications [89]. Treatment should be initiated as soon as a diagnosis is suspected, and within an hour in the case of severe sepsis [22]. Antibiotic choice should depend on the most likely source of infection, immune status of the patient, and the likelihood of opportunistic or resistant organisms.

In general, the gastrointestinal tract is sterile in the stomach and duodenum, with enteric gram negatives in 
the proximal small bowel, and anaerobes populating the distal ileum and colon [7]. Table 1 lists the expected organisms according to source of contamination.

In cases where the source is known, antimicrobial selection can target site-specific organisms. When the source is not known, choice of antimicrobial regimen and duration of treatment should be guided by patient risk. Risk, in this context, is intended to describe risk for failure of treatment, and risk assessment allows for proper selection of narrow versus broad-spectrum antibiotics. High versus low risk is determined primarily by patient physiology and underlying medical conditions (Table 2). Health care-associated infections, APACHE II score $>15$, advanced age, organ dysfunction, poor nutritional status, immunosuppression and presence of malignancy are all associated with a high risk of treatment failure $[5,12]$.

Without identifiable risk factors, an IAI is considered low risk and can be treated with narrow-spectrum antibiotics directed toward anaerobic and gram-negative organisms [7]. In low risk infections, cultures are generally considered unnecessary. Even if cultures are obtained and show resistant organisms, there is no need to alter antimicrobial therapy according to culture results if there is an adequate clinical response [5]. Table 3 lists antibiotic regimens deemed appropriate for low risk patients by the Surgical Infection Society (SIS).

High-risk patients require the use of broad-spectrum antibiotics with anticipation of resistant organisms (see Table 3). Additionally, in high-risk patients attention should be given to the antibiograms of the particular institution, with initial antibiotic choice tailored to the risk of methicillin or vancomycin resistant organisms, and extended spectrum beta lactamase producers. Compared to patients initially treated with broad-spectrum antibiotics, patients who receive inadequate empiric treatment have longer hospital stays, higher rates of postoperative abscesses and re-operation, and increased mortality [90,91]. Furthermore, changing regimens in response to cultures that display resistance does not improve outcomes [90]. Therefore, the use of broaderspectrum agents from the outset appears crucial to optimizing outcomes in high-risk patients. While cultures do not alter outcomes in high risk patients, it is

Table 2 Risk factors for poor outcomes

\begin{tabular}{ll}
\hline $\begin{array}{l}\text { Factors associated with high risk for poor outcomes } \\
\text { Pre-existing factors }\end{array}$ & Disease specific \\
\hline Poor nutritional status & APACHE II score $\geq 15$ \\
Presence of malignancy & Delay in initial intervention $>24$ hours \\
Organ dysfunction & Inadequate source control \\
Immunosuppression & Prolonged pre-operative hospital stay \\
& Prolonged pre-operative antibiotics \\
\hline
\end{tabular}

Adapted from Weigelt JA, Solomkin, Wacha $[4,12,40,109]$.
Table 3 Risk stratified antibiotic recommendations

\begin{tabular}{lll}
\hline & Low Risk & High Risk \\
\hline Single Agent & Cefoxitin & Imipenem-cilastatin \\
& Ertapenem & Meropenem \\
& Moxifloxacin & Doripenem \\
& Ticarcillin & Pipercillin-tazobactam \\
& Tigecycline & \\
Combination & Cefazolin & Cefepime \\
& Cefuroxime & Ceftazidime \\
& Ceftriaxone & Ciprofloxacin \\
& Cefotaxime & Levofloxacin \\
& Ciprofloxacin & +Metronidazole \\
& Levofloxacin & \\
& + Metronidazole & \\
\hline
\end{tabular}

Adapted from Solomkin[4,5] (Infectious Diseases Society of America Guidelines).

recommended that cultures be obtained in this group in order to de-escalate antibiotic therapy to avoid increasing resistance [40].

\section{Infections that Require Special Consideration MRSA}

Though an uncommon cause of IAI, MRSA deserves special consideration. Treatment often includes vancomycin, which has a low bactericidal activity and achievable tissue concentrations of the drug may not meet the minimum inhibitory concentration (MIC) [92]. As a result, these infections may require longer courses of antimicrobial therapy [89]. Continuous infusion of vancomycin may be a solution to this problem. In addition, newer antibacterials such as linezolid, tigecycline, ertapenem, and moxifloxacin are also promising, and have demonstrated non-inferiority in several studies of IAI [40,92-95].

\section{Enterococcus}

The use of antibiotic therapy for Enterococcus in IAI is controversial. Enterococcus can often be isolated from IAI, and is associated with increased risk of treatment failure and higher mortality [96,97]. However, outcomes in these patients have shown to be independent of antibiotic coverage for enterococcus $[97,98]$. Currently, the general consensus regarding enterococcal coverage is that community-acquired infections require no coverage, however ampicillin, or vancomycin should be added to cover the following high risk patient groups: 1) patients in septic shock who have received prolonged treatment with cephalosporins or other antibiotics that select for Enterococcus, 2) immunocompromised patients, 3) patients with prosthetic heart valves, or other intravascular prosthetic devices, or 4) patients with health care associated/recurrent intra-abdominal infection [40,99]. Finally, vancomycin resistant enterococcal (VRE) infections occur in patients who are immunocompromised, previously colonized with 
VRE or treated with vancomycin [100]. In these circumstances VRE should be suspected and treated with alternatives such as linezolid, tigecycline, or daptomycin. In the absence of these risk factors, specific coverage for VRE is not recommended [40].

\section{Candida}

Candida is similar to Enterococcus, in that isolation of Candida from intra-abdominal cultures is associated with increased mortality, but anti-fungal treatment has not been shown to alter this risk [101]. Therefore, fungal coverage is unnecessary unless the patient is immunocompromised, has a severe IAI with Candida grown from intra-abdominal cultures, or has perforation of a gastric ulcer while on acid suppressive medications [102]. Fluconazole is an appropriate initial choice for Candida albicans peritonitis. However, increasingly, non-albicans Candida spp., with resistance to commonly used antifungals are responsible for candidemia [103,104]. Studies have shown that echinocandins are both safe and effective in the treatment of invasive candidiasis. Therefore, in critically ill patients echinocandins, such as caspofungin or echinofungin, should be considered for primary treatment $[102,104]$. Required treatment duration for Candida peritonitis is $2-3$ weeks [102].

\section{Duration of Treatment}

Because resistant organisms have been linked to imprudent use of antibiotics, it is important to limit the duration of antimicrobial treatment [105]. Previously, studies have suggested limiting treatment duration for IAI by discontinuing antibiotics when fever and leukocytosis have resolved, and the patient is tolerating an oral diet [106]. More recently, it has been suggested that fixed duration treatment has similar efficacy [107]. The Surgical Infection Society (SIS) recommends that duration for complicated abdominal infections should be limited to 4-7 days, and may be discontinued sooner in the absence of clinical signs of infection [40]. In addition, once patients are able to tolerate oral intake, antibiotic therapy can be transitioned to oral dosing for the remainder of their treatment without increased risk of failure [108]. Suggested oral regimens for patients in whom resistance is not a concern are listed in Table 4. Of note, lack of resolution of clinical signs of infection after 7 days of antibiotics implies failed source control, tertiary peritonitis, or new infection.

Table 4 Recommended oral regimens

\begin{tabular}{ll}
\hline Oral regimens & \\
Single agent & Double agent \\
\hline Amoxicillin-clavulinic & $\begin{array}{l}\text { Moxifloxacin/Ciprofloxacin/Levofloxacin } \\
\text { acid }\end{array}$ \\
& Oral cephalosporin +Metronidazole \\
\hline
\end{tabular}

Adapted from Solomkin[4] (Guidelines by the Surgical Infection Society and the Infectious Diseases Society of America).
Table 5 Conditions requiring less than 24 hours of antibiotic therapy

\begin{tabular}{ll}
\hline $\begin{array}{l}\text { Conditions requiring }<\mathbf{2 4} \text { hours of antibiotic therapy } \\
\text { Trauma }\end{array}$ & Non-trauma \\
\hline $\begin{array}{l}\text { Bowel injuries due to blunt } \\
\text { trauma repaired in }<12 \text { hours }\end{array}$ & $\begin{array}{l}\text { Acute stomach and proximal jejunal } \\
\text { perforation in the absence of } \\
\text { malignancy or acid reducing } \\
\text { therapy repaired in }<24 \text { hours }\end{array}$ \\
Bowel injuries due to penetrating & $\begin{array}{l}\text { Intraoperative contamination } \\
\text { repaired in }<12 \text { hours }\end{array}$ \\
trauma repaired in $<12$ hours & $\begin{array}{l}\text { Acute appendicitis/cholecystitis } \\
\text { without perforation, abscess or local } \\
\text { peritonitis }\end{array}$
\end{tabular}

Adapted from Solomkin[4](Guidelines by the Surgical Infection Society and the Infectious Diseases Society of America).

Further diagnostic work up including labs, cultures and imaging to look for new or continued sources of infection is essential, and should be accompanied by further surgical intervention if warranted [2].

Finally, we must consider patients with acute IAI, for which prompt source control is achieved. In cases where adequate source control is accomplished within 12-24 hours, less than 24 hours of antibiotic treatment is necessary (Table 5). Antibiotic choice in these instances should generally be guided by the aforementioned recommendations for low risk infections.

\section{Conclusion}

Successful management of IAI is multi-factorial. Source control is of primary importance. Prompt and judicious antibiotic therapy is also necessary. Appropriate antibiotic therapy requires patient risk stratification. Duration of antibiotic treatment should be limited to one week, followed by re-evaluation and intervention as needed.

\section{Author details \\ ${ }^{1} 200$ West Arbor Dr. \#8896, San Diego CA 92103-8896, USA. ${ }^{2}$ Assistant Professor of Surgery, University of California, San Diego, 200 W. Arbor Dr. \#8896, San Diego, CA 92103-8896, USA. ${ }^{3}$ Monroe E. Trout Professor of Surgery, Executive Vice-Chairman, Department of Surgery, Chief, Division of Trauma, Surgical Critical Care, and Burns, University of California, San Diego, 200 West Arbor Dr., \#8896, San Diego, CA 92103-8896, USA}

\section{Authors' contributions}

$\mathrm{NL}$ participated in literature review and preparation of the manuscript. LK participated in literature review and preparation of the manuscript. RC conceived and designed this review and participated in creation of the outline, and preparation of the manuscript. All authors read and approved the final manuscript.

\section{Competing interests}

The authors declare that they have no competing interests.

Received: 10 February 2011 Accepted: 23 February 2011 Published: 23 February 2011

\section{References}

1. Wittmann DH, Schein M, Condon RE: Management of secondary peritonitis. Ann Surg 1996, 224(1):10-18. 
2. Pieracci FM, Barie PS: Management of severe sepsis of abdominal origin Scand J Surg 2007, 96(3):184-196.

3. Merlino Jl, Yowler CJ, Malangoni MA: Nosocomial infections adversely affect the outcomes of patients with serious intraabdominal infections. Surg Infect (Larchmt) 2004, 5(1):21-27.

4. Solomkin JS, Mazuski JE, Bradley JS, Rodvold KA, Goldstein EJ, Baron EJ, O'Neill PJ, Chow AW, Dellinger EP, Eachempati SR, Gorbach S, Hilfiker M, May AK, Nathens AB, Sawyer RG, Bartlett JG: Diagnosis and management of complicated intra-abdominal infection in adults and children: guidelines by the Surgical Infection Society and the Infectious Diseases Society of America. Surg Infect (Larchmt) 11(1):79-109.

5. Solomkin JS, Mazuski JE, Baron EJ, Sawyer RG, Nathens AB, DiPiro JT, Buchman T, Dellinger EP, Jernigan J, Gorbach S, Chow AW, Bartlett J: Guidelines for the selection of anti-infective agents for complicated intra-abdominal infections. Clin Infect Dis 2003, 37(8):997-1005.

6. Sola R, Soriano G: Why do bacteria reach ascitic fluid? Eur J Gastroenterol Hepatol 2002, 14(4):351-354

7. Marshall $\mathrm{JC}$, Innes $\mathrm{M}$ : Intensive care unit management of intra-abdominal infection. Crit Care Med 2003, 31(8):2228-2237.

8. Williams JD, Coles GA: Gram-positive infections related to CAPD. $J$ Antimicrob Chemother 1991, 27(Suppl):B31-35.

9. Ljubicic N, Spajic D, Vrkljan MM, Altabas V, Doko M, Zovak M, Gacina P, Mihatov $S$ : The value of ascitic fluid polymorphonuclear cell count determination during therapy of spontaneous bacterial peritonitis in patients with liver cirrhosis. Hepatogastroenterology 2000, 47(35):1360-1363.

10. Adam EJ, Page JE: Intra-abdominal sepsis: the role of radiology. Baillieres Clin Gastroenterol 1991, 5 (3 Pt 1):587-609.

11. Crandall M, West MA: Evaluation of the abdomen in the critically ill patient: opening the black box. Curr Opin Crit Care 2006, 12(4):333-339.

12. Weigelt JA: Empiric treatment options in the management of complicated intra-abdominal infections. Cleve Clin J Med 2007, 74(Suppl 4):S29-37.

13. Nathens $A B$, Rotstein $O D$, Marshall JC: Tertiary peritonitis: clinical features of a complex nosocomial infection. World J Surg 1998, 22(2):158-163.

14. Henderson LW, Nolph KD: Altered permeability of the peritoneal membrane after using hypertonic peritoneal dialysis fluid. J Clin Invest 1969, 48(6):992-1001.

15. Heemken R, Gandawidjaja L, Hau T: Peritonitis: pathophysiology and local defense mechanisms. Hepatogastroenterology 1997, 44(16):927-936.

16. Hall JC, Heel KA, Papadimitriou JM, Platell C: The pathobiology of peritonitis. Gastroenterology 1998, 114(1):185-196.

17. Brinkmann V, Reichard U, Goosmann C, Fauler B, Uhlemann Y, Weiss DS, Weinrauch $Y$, Zychlinsky A: Neutrophil extracellular traps kill bacteria. Science 2004, 303(5663):1532-1535.

18. Bone RC, Balk RA, Cerra FB, Dellinger RP, Fein AM, Knaus WA, Schein RM, Sibbald WJ: Definitions for sepsis and organ failure and guidelines for the use of innovative therapies in sepsis. The ACCP/SCCM Consensus Conference Committee. American College of Chest Physicians/Society of Critical Care Medicine. Chest 1992, 101(6):1644-1655.

19. Sartelli M: A focus on intra-abdominal infections. World J Emerg Surg 59.

20. Lamke $L O$, Nilsson $G$, Reithner $L$ : The influence of elevated body temperature on skin perspiration. Acta Chir Scand 1980, 146(2):81-84.

21. Reithner $L$ : Insensible water loss from the respiratory tract in patients with fever. Acta Chir Scand 1981, 147(3):163-167.

22. Dellinger RP, Levy MM, Carlet JM, Bion J, Parker MM, Jaeschke R, Reinhart $K$, Angus DC, Brun-Buisson C, Beale R, Calandra T, Dhainaut JF, Gerlach H, Harvey M, Marini JJ, Marshall J, Ranieri M, Ramsay G, Sevransky J, Thompson BT, Townsend S, Vender JS, Zimmerman JL, Vincent JL: Surviving Sepsis Campaign: international guidelines for management of severe sepsis and septic shock: 2008. Crit Care Med 2008, 36(1):296-327.

23. Vincent $\mathrm{J}$, Gerlach $\mathrm{H}$ : Fluid resuscitation in severe sepsis and septic shock: an evidence-based review. Crit Care Med 2004, 32(11 Suppl): S451-454.

24. Yu M, Burchell S, Hasaniya NW, Takanishi DM, Myers SA, Takiguchi SA: Relationship of mortality to increasing oxygen delivery in patients $>$ or $=50$ years of age: a prospective, randomized trial. Crit Care Med 1998, 26(6):1011-1019.

25. Levy B: Lactate and shock state: the metabolic view. Curr Opin Crit Care 2006, 12(4):315-321.
26. James JH, Luchette FA, McCarter FD, Fischer JE: Lactate is an unreliable indicator of tissue hypoxia in injury or sepsis. Lancet 1999, 354(9177):505-508

27. Mikulaschek A, Henry SM, Donovan R, Scalea TM: Serum lactate is not predicted by anion gap or base excess after trauma resuscitation. $J$ Trauma 1996, 40(2):218-222, discussion 222-214.

28. Rutherford EJ, Morris JA Jr, Reed GW, Hall KS: Base deficit stratifies mortality and determines therapy. J Trauma 1992, 33(3):417-423.

29. Davis JW, Shackford SR, Mackersie RC, Hoyt DB: Base deficit as a quide to volume resuscitation. J Trauma 1988, 28(10):1464-1467.

30. Hemming A, Davis NL, Robins RE: Surgical versus percutaneous drainage of intra-abdominal abscesses. Am J Surg 1991, 161(5):593-595.

31. Bufalari A, Giustozzi G, Moggi L: Postoperative intraabdominal abscesses: percutaneous versus surgical treatment. Acta Chir Belg 1996, 96(5):197-200

32. Sugimoto K, Hirata M, Kikuno T, Takishima T, Maekawa K, Ohwada T: Largevolume intraoperative peritoneal lavage with an assistant device for treatment of peritonitis caused by blunt traumatic rupture of the small bowel. J Trauma 1995, 39(4):689-692.

33. Whiteside OJ, Tytherleigh MG, Thrush S, Farouk R, Galland RB: Intraoperative peritoneal lavage-who does it and why? Ann R Coll Surg Engl 2005, 87(4):255-258.

34. Schein M, Gecelter G, Freinkel W, Gerding H, Becker PJ: Peritoneal lavage in abdominal sepsis. A controlled clinical study. Arch Surg 1990, 125(9):1132-1135.

35. Hudspeth AS: Radical surgical debridement in the treatment of advanced generalized bacterial peritonitis. Arch Surg 1975, 110(10):1233-1236.

36. Polk HC Jr, Fry DE: Radical peritoneal debridement for established peritonitis. The results of a prospective randomized clinical trial. Ann Surg 1980, 192(3):350-355.

37. Schilling MK, Maurer CA, Kollmar O, Buchler MW: Primary vs. secondary anastomosis after sigmoid colon resection for perforated diverticulitis (Hinchey Stage III and IV) a prospective outcome and cost analysis. Dis Colon Rectum 2001, 44(5):699-703, discussion 703-695.

38. Solomkin JS, Mazuski JE, Bradley JS, Rodvold KA, Goldstein EJ, Baron EJ, O'Neill PJ, Chow AW, Dellinger EP, Eachempati SR, Gorbach S, Hilfiker M, May AK, Nathens AB, Sawyer RG, Bartlett JG: Diagnosis and management of complicated intra-abdominal infection in adults and children: guidelines by the Surgical Infection Society and the Infectious Diseases Society of America. Clin Infect Dis 50(2):133-164.

39. Humes D, Speake WJ, Simpson J: Appendicitis. Clin Evid (Online) 2007, 2007

40. Solomkin JS, Mazuski J: Intra-abdominal sepsis: newer interventional and antimicrobial therapies. Infect Dis Clin North Am 2009, 23(3):593-608.

41. Lee SL, Walsh AJ, Ho HS: Computed tomography and ultrasonography do not improve and may delay the diagnosis and treatment of acute appendicitis. Arch Surg 2001, 136(5):556-562.

42. Lee SL, Ho HS: Ultrasonography and computed tomography in suspected acute appendicitis. Semin Ultrasound CT MR 2003, 24(2):69-73.

43. Brown MA: Imaging acute appendicitis. Semin Ultrasound CT MR 2008, 29(5):293-307.

44. Lee JH: Sonography of acute appendicitis. Semin Ultrasound CT MR 2003, 24(2):83-90.

45. Sivit CJ, Applegate KE: Imaging of acute appendicitis in children. Semin Ultrasound CT MR 2003, 24(2):74-82

46. Wan MJ, Krahn M, Ungar WJ, Caku E, Sung L, Medina LS, Doria AS: Acute appendicitis in young children: cost-effectiveness of US versus $C T$ in diagnosis-a Markov decision analytic model. Radiology 2009, 250(2):378-386.

47. Kaneko K, Tsuda M: Ultrasound-based decision making in the treatment of acute appendicitis in children. J Pediatr Surg 2004, 39(9):1316-1320.

48. Hagendorf BA, Clarke JR, Burd RS: The optimal initial management of children with suspected appendicitis: a decision analysis. $J$ Pediatr Surg 2004, 39(6):880-885.

49. Pedrosa I, Levine D, Eyvazzadeh AD, Siewert B, Ngo L, Rofsky NM: MR imaging evaluation of acute appendicitis in pregnancy. Radiology 2006, 238(3):891-899.

50. Mason RJ: Surgery for appendicitis: is it necessary? Surg Infect (Larchmt) 2008, 9(4):481-488

51. Sauerland S, Lefering R, Neugebauer EA: Laparoscopic versus open surgery for suspected appendicitis. Cochrane Database Syst Rev 2002, , 1 : CD001546. 
52. Katkhouda N, Mason RJ, Towfigh S, Gevorgyan A, Essani R: Laparoscopic versus open appendectomy: a prospective randomized double-blind study. Ann Surg 2005, 242(3):439-448, discussion 448-450.

53. Kehagias I, Karamanakos SN, Panagiotopoulos S, Panagopoulos K, Kalfarentzos F: Laparoscopic versus open appendectomy: which way to go? World J Gastroenterol 2008, 14(31):4909-4914.

54. Bennett J, Boddy A, Rhodes M: Choice of approach for appendicectomy. Surg Laparosc Endosc Percutan Techa meta-analysis of open versus laparoscopic appendicectomy 2007, 17(4):245-255.

55. Eypasch E, Sauerland S, Lefering R, Neugebauer EA: Laparoscopic versus open appendectomy: between evidence and common sense. Dig Surg 2002, 19(6):518-522.

56. Kapischke M, Caliebe A, Tepel J, Schulz T, Hedderich J: Open versus laparoscopic appendicectomy: a critical review. Surg Endosc 2006, 20(7):1060-1068

57. Andersson RE, Petzold MG: Nonsurgical treatment of appendiceal abscess or phlegmon: a systematic review and meta-analysis. Ann Surg 2007, 246(5):741-748.

58. St Peter SD, Aguayo P, Fraser JD, Keckler SJ, Sharp SW, Leys CM, Murphy JP, Snyder CL, Sharp RJ, Andrews WS, Holcomb GW, Ostlie DJ: Initial laparoscopic appendectomy versus initial nonoperative management and interval appendectomy for perforated appendicitis with abscess: a prospective, randomized trial. J Pediatr Surg 45(1):236-240.

59. Deakin $D E$, Ahmed I: Interval appendicectomy after resolution of adult inflammatory appendix mass-is it necessary? Surgeon 2007, 5(1):45-50.

60. Manuel D, Cutler A, Goldstein J, Fennerty MB, Brown K: Decreasing prevalence combined with increasing eradication of Helicobacter pylori infection in the United States has not resulted in fewer hospital admissions for peptic ulcer disease-related complications. Aliment Pharmacol Ther 2007, 25(12):1423-1427.

61. Wang YR, Richter JE, Dempsey DT: Trends and outcomes of hospitalizations for peptic ulcer disease in the United States, 1993 to 2006. Ann Surg 251(1):51-58.

62. Kleeff J, Friess H, Buchler MW: How Helicobacter Pylori changed the life of surgeons. Dig Surg 2003, 20(2):93-102

63. Ford AC, Delaney BC, Forman D, Moayyedi P: Eradication therapy for peptic ulcer disease in Helicobacter pylori positive patients. Cochrane Database Syst Rev 2006, , 2: CD003840.

64. Svanes C: Trends in perforated peptic ulcer: incidence, etiology, treatment, and prognosis. World J Surg 2000, 24(3):277-283.

65. Lau WY, Leung KL, Kwong KH, Davey IC, Robertson C, Dawson JJ, Chung SC, Li AK: A randomized study comparing laparoscopic versus open repair of perforated peptic ulcer using suture or sutureless technique. Ann Surg 1996, 224(2):131-138.

66. Crofts TJ, Park KG, Steele RJ, Chung SS, Li AK: A randomized trial of nonoperative treatment for perforated peptic ulcer. N Engl J Med 1989, 320(15):970-973.

67. Millat B, Fingerhut A, Borie F: Surgical treatment of complicated duodenal ulcers: controlled trials. World J Surg 2000, 24(3):299-306.

68. Berne TV, Donovan AJ: Nonoperative treatment of perforated duodenal ulcer. Arch Surg 1989, 124(7):830-832.

69. Schoetz DJ Jr: Diverticular disease of the colon: a century-old problem. Dis Colon Rectum 1999, 42(6):703-709.

70. Hughes LE: Postmortem survey of diverticular disease of the colon. II. The muscular abnormality of the sigmoid colon. Gut 1969, 10(5):344-351.

71. Evans J, Kozol R, Frederick W, Voytavich A, Pennoyer W, Lukianoff A, Lardner J: Does a 48-hour rule predict outcomes in patients with acute sigmoid diverticulitis? J Gastrointest Surg 2008, 12(3):577-582.

72. Sra HK, Shipman K, Virk HS: Does a 48-hour rule predict outcomes in patients with acute sigmoid diverticulitis? J Gastrointest Surg 2009, 13(10):1892.

73. Kaiser AM, Jiang JK, Lake JP, Ault G, Artinyan A, Gonzalez-Ruiz C, Essani R, Beart RW Jr: The management of complicated diverticulitis and the role of computed tomography. Am J Gastroenterol 2005, 100(4):910-917.

74. Ambrosetti $P$, Becker C, Terrier F: Colonic diverticulitis: impact of imaging on surgical management - a prospective study of 542 patients. Eur Radiol 2002, 12(5):1145-1149.

75. Brandt D, Gervaz P, Durmishi Y, Platon A, Morel P, Poletti PA: Percutaneous CT scan-guided drainage vs. antibiotherapy alone for Hinchey II diverticulitis: a case-control study. Dis Colon Rectum 2006, 49(10):1533-1538.
76. Siewert B, Tye G, Kruskal J, Sosna J, Opelka F, Raptopoulos V, Goldberg SN: Impact of CT-guided drainage in the treatment of diverticular abscesses: size matters. AJR Am J Roentgenol 2006, 186(3):680-686.

77. Golfieri R, Cappelli A: Computed tomography-guided percutaneous abscess drainage in coloproctology: review of the literature. Tech Coloproctol 2007, 11(3):197-208.

78. Ambrosetti P, Chautems R, Soravia C, Peiris-Waser N, Terrier F: Long-term outcome of mesocolic and pelvic diverticular abscesses of the left colon: a prospective study of 73 cases. Dis Colon Rectum 2005, 48(4):787-791.

79. Chapman J, Davies M, Wolff B, Dozois E, Tessier D, Harrington J, Larson D: Complicated diverticulitis: is it time to rethink the rules? Ann Surg 2005, 242(4):576-581, discussion 581-573.

80. Salem TA, Molloy RG, O'Dwyer PJ: Prospective study on the management of patients with complicated diverticular disease. Colorectal Dis 2006, 8(3):173-176.

81. Ricciardi R, Baxter NN, Read TE, Marcello PW, Hall J, Roberts PL: Is the decline in the surgical treatment for diverticulitis associated with an increase in complicated diverticulitis? Dis Colon Rectum 2009, 52(9):1558-1563.

82. Salem L, Anaya DA, Roberts KE, Flum DR: Hartmann's colectomy and reversal in diverticulitis: a population-level assessment. Dis Colon Rectum 2005, 48(5):988-995.

83. Salem L, Flum DR: Primary anastomosis or Hartmann's procedure for patients with diverticular peritonitis? A systematic review. Dis Colon Rectum 2004, 47(11):1953-1964.

84. Chandra V, Nelson H, Larson DR, Harrington JR: Impact of primary resection on the outcome of patients with perforated diverticulitis. Arch Surg 2004, 139(11):1221-1224

85. Aydin HN, Remzi FH, Tekkis PP, Fazio WW: Hartmann's reversal is associated with high postoperative adverse events. Dis Colon Rectum 2005, 48(11):2117-2126

86. Richter S, Lindemann W, Kollmar O, Pistorius GA, Maurer CA, Schilling MK. One-stage sigmoid colon resection for perforated sigmoid diverticulitis (Hinchey stages III and IV). World J Surg 2006, 30(6):1027-032.

87. McCafferty $\mathrm{MH}$, Roth $\mathrm{L}$, Jorden J: Current management of diverticulitis. Am Surg 2008, 74(11):1041-1049.

88. Klarenbeek $B R$, Veenhof $A A$, Bergamaschi $R$, van der Peet $D L$, van den Broek WT, de Lange ES, Bemelman WA, Heres P, Lacy AM, Engel AF, Cuesta MA: Laparoscopic sigmoid resection for diverticulitis decreases major morbidity rates: a randomized control trial: short-term results of the Sigma Trial. Ann Surg 2009, 249(1):39-44.

89. Blot S, De Waele JJ: Critical issues in the clinical management of complicated intra-abdominal infections. Drugs 2005, 65(12):1611-1620.

90. Mosdell DM, Morris DM, Voltura A, Pitcher DE, Twiest MW, Milne RL, Miscall BG, Fry DE: Antibiotic treatment for surgical peritonitis. Ann Surg 1991, 214(5):543-549.

91. Montravers P, Gauzit R, Muller C, Marmuse JP, Fichelle A, Desmonts JM: Emergence of antibiotic-resistant bacteria in cases of peritonitis after intraabdominal surgery affects the efficacy of empirical antimicrobial therapy. Clin Infect Dis 1996, 23(3):486-494.

92. Stass $H$, Rink AD, Delesen $H$, Kubitza D, Vestweber $\mathrm{KH}$ : Pharmacokinetic and peritoneal penetration of moxifloxacin in peritonitis. $J$ Antimicrob Chemother 2006, 58(3):693-696.

93. Vuagnat A, Stern R, Lotthe A, Schuhmacher $H$, Duong M, Hoffmeyer $P$, Bernard L: High dose vancomycin for osteomyelitis: continuous vs. intermittent infusion. J Clin Pharm Ther 2004, 29(4):351-357.

94. Babinchak T, Ellis-Grosse E, Dartois N, Rose GM, Loh E: The efficacy and safety of tigecycline for the treatment of complicated intra-abdominal infections: analysis of pooled clinical trial data. Clin Infect Dis 2005, 41(Suppl 5):S354-367.

95. Solomkin JS, Yellin AE, Rotstein OD, Christou NV, Dellinger EP, Tellado JM, Malafaia O, Fernandez A, Choe KA, Carides A, Satishchandran V, Teppler H: Ertapenem versus piperacillin/tazobactam in the treatment of complicated intraabdominal infections: results of a double-blind, randomized comparative phase III trial. Ann Surg 2003, 237(2):235-245.

96. Burnett RJ, Haverstock DC, Dellinger EP, Reinhart HH, Bohnen JM, Rotstein OD, Vogel SB, Solomkin JS: Definition of the role of enterococcus in intraabdominal infection: analysis of a prospective randomized trial. Surgery 1995, 118(4):716-721, discussion 721-713.

97. Sitges-Serra A, Lopez MJ, Girvent M, Almirall S, Sancho JJ: Postoperative enterococcal infection after treatment of complicated intra-abdominal sepsis. Br J Surg 2002, 89(3):361-367. 
98. Teppler H, McCarroll K, Gesser RM, Woods GL: Surgical infections with enterococcus: outcome in patients treated with ertapenem versus piperacillin-tazobactam. Surg Infect (Larchmt) 2002, 3(4):337-349.

99. Harbarth S, Uckay I: Are there patients with peritonitis who require empiric therapy for enterococcus? Eur J Clin Microbiol Infect Dis 2004, 23(2):73-77.

100. Mazuski JE: Vancomycin-resistant enterococcus: risk factors, surveillance, infections, and treatment. Surg Infect (Larchmt) 2008, 9(6):567-571.

101. Sandven P, Qvist H, Skovlund E, Giercksky KE: Significance of Candida recovered from intraoperative specimens in patients with intraabdominal perforations. Crit Care Med 2002, 30(3):541-547.

102. Pappas PG, Rex JH, Sobel JD, Filler SG, Dismukes WE, Walsh TJ, Edwards JE: Guidelines for treatment of candidiasis. Clin Infect Dis 2004, 38(2):161-189.

103. Krause DS, Reinhardt J, Vazquez JA, Reboli A, Goldstein BP, Wible M, Henkel T: Phase 2, randomized, dose-ranging study evaluating the safety and efficacy of anidulafungin in invasive candidiasis and candidemia. Antimicrob Agents Chemother 2004, 48(6):2021-2024.

104. Pfaller MA, Messer SA, Hollis RJ, Boyken L, Tendolkar S, Kroeger J, Diekema DJ: Variation in susceptibility of bloodstream isolates of Candida glabrata to fluconazole according to patient age and geographic location in the United States in 2001 to 2007. J Clin Microbiol 2009, 47(10):3185-3190.

105. Leaper D: Nosocomial infection. Br J Surg 2004, 91(5):526-527.

106. Stone HH, Bourneuf AA, Stinson LD: Reliability of criteria for predicting persistent or recurrent sepsis. Arch Surg 1985, 120(1):17-20.

107. Hedrick TL, Evans HL, Smith RL, McElearney ST, Schulman AS, Chong TW, Pruett TL, Sawyer RG: Can we define the ideal duration of antibiotic therapy? Surg Infect (Larchmt) 2006, 7(5):419-432.

108. Solomkin JS, Dellinger EP, Bohnen JM, Rostein OD: The role of ora antimicrobials for the management of intra-abdominal infections. New Horiz 1998, 6(2 Suppl):S46-52.

109. Wacha H, Hau T, Dittmer R, Ohmann C: Risk factors associated with intraabdominal infections: a prospective multicenter study. Peritonitis Study Group. Langenbecks Arch Surg 1999, 384(1):24-32.

doi:10.1186/1749-7922-6-7

Cite this article as: Lopez et al:: A Comprehensive review of abdominal infections. World Journal of Emergency Surgery 2011 6:7.

\section{Submit your next manuscript to BioMed Central and take full advantage of:}

- Convenient online submission

- Thorough peer review

- No space constraints or color figure charges

- Immediate publication on acceptance

- Inclusion in PubMed, CAS, Scopus and Google Scholar

- Research which is freely available for redistribution

Submit your manuscript at www.biomedcentral.com/submit 